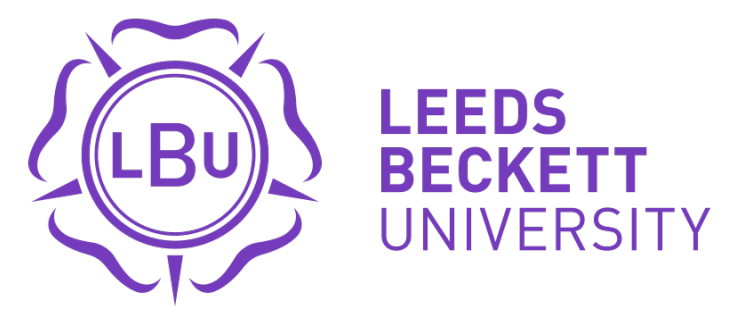

Citation:

Stride, A and Flintoff, A (2016) 'I don't want my parents' respect going down the drain': South Asian, Muslim young women negotiating family and physical activity. Asia-Pacific Journal of Health, Sport and Physical Education. ISSN 1837-7122 DOI: https://doi.org/10.1080/18377122.2016.1240592

Link to Leeds Beckett Repository record:

https://eprints.leedsbeckett.ac.uk/id/eprint/3107/

Document Version:

Article (Accepted Version)

This is an Accepted Manuscript of an article published by Taylor \& Francis in Asia-Pacific Journal of Health, Sport and Physical Education on 06 October 2016, available online: http://www.tandfonline.com/10.1080/18377122.2016.1240592

The aim of the Leeds Beckett Repository is to provide open access to our research, as required by funder policies and permitted by publishers and copyright law.

The Leeds Beckett repository holds a wide range of publications, each of which has been checked for copyright and the relevant embargo period has been applied by the Research Services team.

We operate on a standard take-down policy. If you are the author or publisher of an output and you would like it removed from the repository, please contact us and we will investigate on a case-by-case basis.

Each thesis in the repository has been cleared where necessary by the author for third party copyright. If you would like a thesis to be removed from the repository or believe there is an issue with copyright, please contact us on openaccess@leedsbeckett.ac.uk and we will investigate on a case-by-case basis. 
TITLE: 'I don't want my parents' respect going down the drain': South Asian, Muslim young women negotiating family and physical activity.

AUTHORS: Annette Stride* \& Anne Flintoff

School of Sport, Carnegie Faculty, Leeds Beckett University, Leeds, England

*Corresponding author: a.stride@leedsbeckett.ac.uk 



\begin{abstract}
Young women's relationship with physical activity has been explored extensively, yet the focus is often upon young women who are White. This paper considers South Asian, Muslim young women's experiences of physical activity and how these are influenced by family. A 'middle ground' feminist approach is used, drawing upon the work of Hill Collins (2000) and Hamzeh (2012). Data were generated with 13 young women using participatory approaches in focus group settings, and individual interviews. This research highlights how the young women's families can both enable and challenge opportunities and involvement in physical activity. The paper discusses how gender and religion intersect with family and wider community to influence experiences in multiple, diverse and fluid ways. The young women's narratives suggest that experiences are not determined solely by these influences; rather, they emerge as active agents negotiating different contextual challenges in their quest to be physically active.
\end{abstract}

KEY WORDS: gender; ethnicity; Muslim; young women; family; physical activity

\title{
Introduction
}

The family has long been recognised as an important site for socialisation including the development of physical activity interests as part of leisure (Haycock \& Smith, 2012; Rapoport \& Rapoport, 1975; Wheeler, 2011). It is also acknowledged that gender, class, disability and ethnicity are important in influencing sports and physical activity involvement (Department for Culture Media \& Sport, 2011). Indeed, the identification of particular groups, including women and girls and members of minority ethnic communities, as under-represented and 'problematic' in relation to sports participation, has led to extensive research. However, there is little empirical research exploring these multiple identities in combination. This impedes our understandings of the sport and physical activity experiences of young women from 
minority ethnic communities. However, this gap is beginning to be addressed through the work of a small group of scholars. For example, Dagkas, Benn and Jawad (2011) and Stride (2014a; 2014b) exploring Muslim young women's experiences of school Physical Education (PE); and research focusing on minority ethnic young women's broader experiences of physical activity (Azzarito \& Hill, 2013; Hamzeh, 2011; 2012; Knez, Macdonald, \& Abbott, 2012). Yet, this work remains at the margins of scholarly thought in comparison to the extensive research that considers White women's and girls' experiences.

This paper seeks to contribute to the work of these scholars by considering the ways in which the relationship between family, gender and ethnicity influences the out of school physical activity experiences of a group of South Asian, Muslim young women based in England. It focuses upon the ways in which the family challenges and enables the young women's involvement in physical activity; how the young women navigate challenges and negotiate opportunities, and the ways in which the family intersects with other influences including religion, culture and wider community. At this point it is important to add a cautionary note regarding the labels 'South Asian', and 'Muslim'. These terms should not be read as indicators of a homogenous group. For example, the significance of history, including country and region of origin, the length of time the family have resided in the UK, and links to their home country contribute to the diversity found within Muslim families and communities (Shain, 2003). Research also highlights the importance of different cultures, degrees of religiosity (the extent to which a person regards themselves as religious), and differing interpretations of Islam in contributing to diverse practices in Muslim communities. For example, different beliefs circulate around the ways in 
which Muslim young women are expected to embody their religion, as well as their involvement in physical activity (Benn, Pfister, \& Jawad, 2011).

The organisation of the paper is as follows; to begin, there is a consideration of the connections between the family and physical activity involvement, focusing specifically on research that explores the experiences of Asian and/ or Muslim young women. This is followed by a discussion of the theoretical resources that inform this paper, including 'middle ground' thinking (Archer, Hutchings, \& Leathwood, 2001), Hill Collins' (2000) matrix of domination, and Hamzeh's (2012) use of the hijab discourse. Lastly, the paper presents the key findings of the research including the diverse ways in which the family enables and challenges the young women in their quest to be physically active, and their agency in negotiating these challenges.

\section{Intersections of the family and physical activity}

The work of the Rapoports (1975) in the UK was pivotal in highlighting the interconnections between the family, work and leisure in influencing an individual's lifestyle throughout the life-cycle. They offer examples of how multiple influences including the family, schooling, friends, and material circumstances work in contradictory and complimentary ways to contribute to diverse sporting and leisure interests and behaviours. Their work has been significant in underpinning current studies that focus upon the family and socialisation into sport and physical activity. A number of these studies highlight the benefits that accrue from a family's involvement in sport and physical activity including: enhanced family functioning (Buswell, Zabriskie, Lundberg, \& Hawkins, 2012); opportunities for children to develop skills such as communication and problem solving (Shaw, 2008); increased bonding between family members (Harrington, 2009), and directing children to 
meaningful activities (Kay, 2009; Shaw, 2008). Others have highlighted the ways in which the family-leisure nexus can create negative experiences. For example, traditional gender roles can be reinforced through family leisure, negatively impacting on women's free time and choices (Shaw, 2008; Trussell \& Shaw, 2012). Shaw (2008) argues that women are usually involved in the 'hidden' work, providing transport, washing sports clothing, and co-ordinating schedules, with fathers involved in more visible, central and active roles such as coaching and organising events (Trussell \& Shaw, 2012; Wheeler, 2011). However, families are not homogenous and there have been calls for research to explore a wider range of family structures and identities, and how these influence physical activity and wider leisure experiences (Shaw, 2008; Trussell \& Shaw, 2012).

An emerging body of scholars are engaging in work exploring the intersections of gender and ethnicity within sport and physical activity contexts. Much of this work identifies the family as significant to opportunities and experiences. For example, Kay's (2006) research highlights how the intersections of family and religion influence young Muslim women's engagement in a sport and education programme. Many family members supported the young women's participation in the programme providing it adhered to the requirements of Islam. Yet, different interpretations of these requirements emerged within the young women's families (for example, the appropriateness of local settings, gender segregated activities and the relevance of higher education). Nevertheless, the young women demonstrated their ability to navigate different interpretations of their religion using various strategies including drawing on mothers, older siblings or religious leaders for support for their involvement in the programme. Family also emerges as significant in Azzarito's and Hill's research (2013). They provide an alternative perspective to 
the dominant storyline of minority ethnic young women's lack of physical activity participation. Using a visual ethnographic approach, they highlight the importance of 'homey' spaces in supporting young women's physicality. Homey spaces are defined as safe, intimate and shielded sites that enable young women's engagement in physical activity and include bedrooms, gardens and living rooms.

The relationship between family and physical activity involvement is also highlighted in Walseth's (2006) study of young Muslim women with immigrant backgrounds living in Norway. Parents were identified as key in both supporting and constraining their daughters' sports involvement. Faced with some constraints, a number of these young women were active in drawing upon the aspects of their religion that they felt articulated the importance of exercise to justify their physical activity involvement. Similarly, Knez et al.'s (2012) study of young Muslim women living in Australia highlights the ways in which parents can support and constrain opportunities. They note how parents are more likely to enable daughters' involvement in broader physical activity pursuits than sporting activities. They explain this finding in relation to traditional understandings of sport as a masculinised activity and therefore an unsuitable pursuit for young women. In addition to parents, siblings and extended family are also identified as important in providing opportunities for experiencing regular and different kinds of physical activities.

Whilst the literature reviewed here identifies the significance of the social structures of family, religion, gender and ethnicity on young women's involvement in physical activity, it also suggests these do not always determine experiences. Indeed, many of the young women demonstrate their agency in constituting a physical identity, and do so by drawing on a range of resources. In recognising the 
significance of both structure and agency, a middle ground approach (Archer et al., 2001 ) is used in this paper to explore these kinds of negotiations.

\section{Middle ground theorising}

Middle ground thinking recognises the compelling arguments of both structural feminist approaches and poststructural debates to understanding gender power relations, without embracing either whole heartedly. For example, whilst earlier feminist theories have undoubtedly developed understandings of gendered power and the subordinated position of women, they are challenged for their focus on social structures, whereby women are viewed as objects of oppression, with their realities, identities, and histories defined by others. Poststructural feminism argues for women to be recognised as active agents in the constitution of their own identities, resisting and challenging power relations (McNay, 1992; Weedon, 1997). Poststructural feminists have also critiqued the earlier approaches for ignoring women's multiple identities, presuming all women have the same experiences and needs (hooks, 1982). Poststructural feminism emphasises individual experiences by acknowledging differences between women (for example, ethnicity, sexuality, disability) and hence contributes to problematising gendered stereotypes. Yet, poststructural feminism is not without its critiques. For example, it is argued that in deconstructing terms such as 'South Asian', 'Muslim' and 'woman', attention is diverted away from the shared experiences of discrimination, and developing resistance as a group becomes problematic (Hill Collins, 2000; McNay, 1992). Within this paper a middle ground approach (Archer et al., 2001) is adopted that recognises both structural and poststructural schools of thought. In using a middle ground lens, the work of Hill Collins' (2000) and Hamzeh (2012) provide useful vantage points. 
Hill Collins' (2000) matrix of domination is one social theory that attempts to acknowledge individual difference and social structures through four domains. Within the 'structural' domain large, social institutions including schools, the labour market, religion and the media intersect, creating an unequal distribution of resources, contributing to minority ethnic young women's subordination. The 'disciplinary' domain focuses on the ways in which power relations are managed. For example, surveillance and bureaucracy are two practices that ensure Muslim women's and girls' bodies are monitored and orderly, disciplined individuals produced. The 'hegemonic' domain considers the relationship between institutional practice and individual experience; for example, how particular groups maintain power through school curricula, religious teachings and the media. Within this domain, common sense ideas are created, against which individuals are judged, leading to subordination and domination. The 'interpersonal' domain focuses on the everyday interactions between individuals and how power relations are created through simplistic notions of difference. Although a useful framework, I believe that more emphasis is placed on structure at the expense of individual experience and action. I have found the matrix useful when complimented through the work of Hamzeh (2012) and her use of the hijab discourse that enables deficit and homogenised ways of thinking about Muslim young women to be challenged.

In her work with four Muslim young women based in the USA, Hamzeh (2011) critiques research that overtly focuses on religious requirements and 'the cultural barrier' to physical activity involvement. She argues that this overlooks other gendered discourses and over-simplifies the multiple, discursive cultural norms that Muslim young women must negotiate in their quest to be physically active. She calls for scholars working with Muslim young women to acknowledge the hijab discourse, 
the 'genderizing discourse that utilizes muslim (author's use of italics ${ }^{1}$ ) females' bodies as sites through which their ways of thinking and acting may be hegemonized' (Hamzeh, 2011, p. 485). Drawing on the work of Mernissi (1992), Hamzeh presents the hijab discourse as having visual, spatial and ethical dimensions that are inscribed on the female Muslim body through a series of interrelated visible and invisible practices, values and norms. She notes that,

\footnotetext{
the hijab is not only the narrow and static visual representation of the headscarf some muslim women wear. It is also the spatial hijab, the border that challenges muslim females' mobility in public spaces, and the ethical hijab, the protector that shelters them from forbiddens, harams, like physical/ sexual encounters with males (Hamzeh, 2011, p. 482).
}

She argues that the hijab discourse is "the hegemonic discourse through which the Muslimah's body became regulated and normalized for centuries" (Hamzeh, 2012, p. 18). Hamzeh $(2011,2012)$ exposes the hijab discourse by problematizing, questioning and countering monolithic interpretations of Islamic sacred texts by Muslims and non-Muslims. Through this 'deveiling' of 'taken-for-granted' hijabs she advocates for more nuanced understandings that recognise the multiple, shifting challenges that Muslim young women negotiate in their daily lives. Alongside these theoretical considerations, a number of key methodological decisions were also made and these are discussed next.

\section{Research methodology}

\section{Research setting.}

Data generation took place within one large, co-educational, local authority secondary school in Yorkshire, England. As a White, non-Muslim researcher I recognised some of the difficulties in gaining access to Muslim communities, so a 
school based setting for this research was a pragmatic choice (Watson \& Scraton, 2001). As a college lecturer in Stonefields ${ }^{2}$, I had some contacts within a number of the local secondary schools. One such contact worked in the PE department of Woodstock High, based in the inner city. This school setting was particularly valuable because of its student demographics. For example, of its 1850 students aged 11-18, 91\% identify as Muslim, and $76 \%$ as British Asian of Pakistani origin3.

\section{Methods}

Within society more broadly, and increasingly within research in PE and physical activity, there is a recognition that young people are experts in their own lives that must be consulted with (Clark \& Moss, 2011). With this shift in thinking comes the recognition that conventional methods such as interviews and questionnaires may not be the most effective means of working with young people (Greig, Taylor, \& MacKay, 2007) and that these require an imaginative rethinking if young people's views are to be captured (Flintoff, Fitzgerald, \& Scraton, 2008). In this respect, researchers in PE and physical activity are increasingly turning to the use of qualitative, participatory approaches to work in more innovative and creative ways with young people (O'Sullivan \& MacPhail, 2010). Within this study, data were initially generated through the creation of a series of research artefacts with 23 young women aged between 14 and 16. These artefacts included posters depicting significant aspects in their lives, maps plotting their movements outside school, and PE boxes illustrating their thoughts and opinions on the subject. Figure 1 provides an example of some of the posters created by the young women.

Figure 1: The young women's posters [TO BE PLACED HERE] 
The creation of the research artefacts took place outside of school or within a focus group setting which also provided a useful space in which to discuss the artefacts. The 23 young women were split into four groups, each group meeting once a week for four weeks in a Personal, Social, Citizenship and Health Education class. On completion of the focus groups, interviews were conducted with 13 of the young women. These 13 were chosen based on their availability to be interviewed and their willingness to continue to be involved in the research. Whilst the majority of the young women agreed to be interviewed, finding time when they and the main researcher were both available proved challenging. Many of the young women were not able to meet before or after school, limiting interview times to lunch and break (recess) times. In conjunction with the researcher's schedule this limited the number of young women involved in the interviews to 13. Although, in the majority of cases this meant interviewing the 13 young women on multiple occasions. Interviews enabled more in-depth discussions to develop around their artefacts and the conversations that had emerged during the focus groups. In combination, the data generated led to more nuanced understandings regarding the fluidity, diversity and complexity of the young women's experiences. Some basic information about the young women and their family arrangements is presented in table 1.

\section{Table 1: The young women and their families [TO BE PLACED HERE)}

\section{Data analysis and representation}

The volume and diversity of data generated, alongside the middle ground approach adopted, influenced the decision to undertake a double level of analysis on the data. The first level of analysis involved adopting the 'storyteller' position (Smith \& Sparkes, 2008) where each individual young woman's multiple data were analysed 
and a dynamic framework used to connect these sources. This led to the creation of a critical non-fictional narrative or story for each young woman (Dowling, 2012). In the construction of the narratives, interview data were cross-referenced back to the other data with field notes and memos used to articulate links. Each young woman's poster and map were drawn upon to develop a narrative's key features, including contexts, plots and characters (Dowling, 2012), and interview quotes were threaded into the storyline.

Whilst the 'storyteller' level of analysis may be sufficient from a poststructural feminist perspective, enabling individualised, diverse stories to be told, leaving narratives to 'speak for themselves' can be problematic (Dowling, 2012). Stories can be read differently which may fail to draw out similarities in experiences, for example, of discrimination and inequality. As Dowling (2012) notes, micro stories about individual lives reflect macro societal relations. In using a middle ground approach to this research, a second level of analysis was required. In adopting the 'story analyst' position, similarities and differences across the young women's narratives in terms of the significance of their family, religion and wider community, and their stories of negotiation and navigating of challenges were excavated (Smith \& Sparkes, 2008). This involved a thematic analysis, following the constant comparison method. Here, all the young women's narratives were read and re-read before being coded. Throughout this process detailed notes and memos were used, leading to the emergence of themes and sub-themes (Lincoln \& Guba, 1985). The following discussion focuses on one theme that emerged from the data, the significance of the family to the young women's out of school physical activity opportunities. As it is beyond the word limit of this paper to present whole narratives, excerpts from the young women's stories are offered to illuminate the findings. 


\section{Discussion: South Asian, Muslim young women, family and physical activity}

From the theme of the family, three key aspects emerged. The first two aspects include the ways in which the family enable opportunities for young women's physical activity, and how the family can present challenges to these opportunities. In this regard the young women's narratives reflect the significance of structure in their daily lives including the family, religion and education. However, the young women's stories also suggest that they are not defined by these structures. In the third aspect the young women emerge as active agents in negotiating family relations and wider influences when considering their physicality.

\section{The family enabling physical activity opportunities}

Support from family members emerges as significant in enabling the young women's physical activity opportunities, similar to findings by Azzarito and Hill (2013) and Knez et al. (2012). This is reflected in various ways in a number of the young women's stories. For example, Bebo's ${ }^{4}$ dad and brothers have taught her new skills in rounders; Borat's aunt provides her with transport into town to enable her participation in a weekly break dance club; and Hannah, Bebo, Borat, Sara, Rihanna, Messa, Mariya and Noreen discuss the value of family members, including parents, siblings, uncles and aunts, in providing someone to play with.

If there's not enough to play rounders, me, my dad and brothers usually play cricket and football. Better than just hanging around chatting. And my dad and brothers have taught me how to play those games 'cause we don't do them in PE (Bebo).

I sometimes play cricket and rounders with the family and friends, cousins like. And I'm alright 'cause of what we learn in PE (Mariya). 
A number of the young women also discuss activities traditionally viewed as nonfeminine in Westernised contexts introduced to them by their family. For example, Sam participates in football,

I play rounders sometimes with my aunts and nephews and nieces, and then we go to the fields by my gran in the summer and play football (Sam).

Similarly, Borat talks about the rugby, cricket and football games she participates in with her dad, brother and uncles. These kinds of experiences had caused her to critically reflect on the kinds of activities offered as part of her school based PE curriculum.

Dunno why we don't play football, or cricket, come to think of it, in PE. Loads of girls wanna do it but we have to do other stuff to the boys. Personally, I think it's unfair and very sexist.

For Sara, she notes her mother's support in challenging a neighbour's beliefs about South Asian, Muslim young women engaging in physical activity with boys.

Some of the older women are a bit more traditional ..... Think that boys and girls shouldn't be playing together and stuff..... Like the other day someone started about Sofia (sister) playing in the street with Ibrahim (friend), but mom was having none of it. She said they're only playing, they're the same age and if my daughter doesn't mind then I don't mind, so don't start a fight about it! She's cool my mom.

From these examples, it is evident that a number of the young women's families facilitate their participation in physical activity in different ways. These include providing transport, coaching, support, and contesting others' beliefs about young women's involvement in physical activity. 
In relation to this last point, the young women's stories reflect how extended family and wider community, alongside multiple interpretations of their religion, can challenge their physical activity opportunities in diverse ways. As Hamzeh (2011; 2012) warns, there is a need for research that moves beyond narrow interpretations of religious requirements and monolithic cultural beliefs when explaining Muslim young women's physical activity experiences. She argues for research to acknowledge the hijab discourse, exposing its visual, spatial and ethical dimensions. As will be seen in the following section, the young women's stories reflect the multidimensional hijab discourse and the various challenges encountered in their physical activity involvement.

\section{Challenges to young women's physical activity opportunities}

The young women in this study were aware of different interpretations of, and beliefs about, their religion circulating in the hegemonic domain (Hill Collins, 2000). Like the young women in Walseth's (2006) research, they noted how immediate and extended family, and wider community members could contribute to these divergences. Moreover, they discussed how different interpretations and beliefs could shape the ways in which they are expected to embody their religion, which in turn, influenced physical activity opportunities and experiences (Kay, 2006; Walseth, 2006). In so doing, the young women's stories reflect the hijab discourse and the various dimensions: visual, spatial and ethical (Hamzeh, 2011; 2012). For example, Noreen's thoughts about swimming with her dad and brothers, and boxing with her siblings and young men, reflect concerns regarding the violation of one or more of the hijabs. 
I used to love swimming with my cousin sisters but they don't go no more ...... And I can't go with my dad and brothers, wouldn't feel right. I wouldn't be happy about it, it'd be embarrassing. And dad'd prefer it for me to go to women's only.

These concerns had led to restrictions on entry to, or the 'veiling-off' of, particular spaces (Hamzeh, 2011). Like Hamzeh's (2012) findings, this 'veiling-off' of spaces was also contingent on the kinds of activities taking place in these contexts, and who else is present. For example, for Noreen the swimming pool with its dress code and presence of young men represents a space that violates the visual and ethical hijabs as constructed by her family. For Sumera, expectations on her to keep up that respect, that holy reputation' of her family had similarly led to her mother 'veiling-off' the street as a place for physical activity. Sumera was aware that her mother's concerns regarding her not conforming to, or crossing, the ethical hijab as interpreted by her family prevented her from playing cricket in the street with a female friend and boys. Sumera also recognises how her actions are surveyed and monitored by relatives and neighbours to ensure she embodies the hijab discourse in appropriate ways. To not do so would mean her crossing the hijabs to bring shame on her family and faith. She is aware of the multiple and shifting nature of the hijabs circulating within her community, noting how the differences between her family and those of her friend influence her dress, behaviour and mobility as a young Muslim woman. Her narrative depicts how the intersections of the disciplinary and hegemonic domains influence her physical activity choices at the interpersonal level (Hill Collins, 2000).

She's (Nisha) not got a care in the world. Does what she wants. Hangs out in the street, goes to the cinema every weekend, talks to boys, all the things I 
can't do really. And nobody stops her. But she hasn't got relatives living in the area. It's just that family thing. My family's different. We have good status 'cause of my granddad and girls have to keep up that respect, that holy reputation. Do their work, study hard and get a good job, don't go out uncovered, don't mess about, no boys or smoking or bad things like that. Just respect boundaries, innit?

Similarly, Sam, Bebo, Mariya and Messa discuss how their behaviour at school can have repercussions on their family's reputation. After being sent to the head teacher for fighting during break time (recess) Bebo reflects,

I don't want my parents' respect going down the drain, I love my parents ..... My dad has brought us up and shown us a lot of respect, so obviously we have to show respect, so they'll be well cross at all this.

This event had sparked a heated discussion amongst Bebo's friends about the appropriateness of Muslim young women's engagement in boxing as a physical activity pursuit. Their debate highlights the multiple, conflicting and shifting expectations regarding the ways in which young Muslim women's bodies are expected to behave in particular spaces; and the different ways in which the visual, spatial and ethical dimensions are encountered and negotiated.

In Islam, a Muslim girl being a boxer is not right for some people. They can do it, they are allowed, but it can look bad on a Muslim family and you want respect for your family. Bebo's parents might agree with it, but with this city and culture thingy, people talk. A lot! ..... Like, if they see you with a boy they turn it into a big deal, when you were just talking (Sam). 
Bebo's narrative provides further evidence of the diversity of interpretations she encounters as she moves within and between different spaces in her life. Whilst she regularly engages in physical activity with boys in the street, she finds herself unable to train in ju-jitsu with men at her local community centre. Despite her father and the ju-jitsu instructor approving of her involvement, her request is denied by the community centre manager. Within this space, the intersections of a particular set of cultural beliefs, and a patriarchal power system conspire to ensure her opportunities are limited and her wishes, and those of other young women, are not granted at the interpersonal level (Hill Collins, 2000).

\footnotetext{
..... the guy in charge of the community centre said he didn't want girls training with men anymore. Even though dad said it was OK, he still stopped us. Even the guy teaching us was happy for us to carry on but he said it's his kinda place, so l've gotta do what he wants. I mean what's done there for girls?
}

Whilst the structures of the family and religion influence the young women's physical activity opportunities, their stories also suggest experiences are not totally determined by them. As discussed next, the young women's stories also reflect agency in the ways they counter the challenges faced.

\section{Young women actively negotiating their physicality}

Whilst the young women's stories reflect the different and shifting interpretations of the hijab discourses encountered, their narratives also suggest they are not passive recipients of these. They exercise their agency in their 'deveiling' of the hijab discourse in diverse ways (Hamzeh, 2011). In other words, the young women counter the hijab discourse through their questioning and critical reflections of 'takenfor-granted' assumptions, and their actions and negotiations to be physically active. 
For example, in Bebo's previous excerpt, her 'deveiling' of the spatial and ethical hijabs is reflected in her questioning of the community centre manager's belief that young women and girls cannot train with men, 'I mean what's done there for girls?' She recognises that this belief should not be mistaken for a 'taken-for-granted' truth, citing the support she had garnered from her father and the ju-jitsu instructor. In deveiling this hijab, she also looks beyond her own experiences, appreciating these are not unique but shared by other young women in her community. Moreover, Bebo does not let these experiences determine her involvement in physical activity, seeking other outlets, including running with her sister, and playing games in the street with family and friends.

Other young women demonstrate their 'deveiling' of the hijab discourse through their resourcefulness and creativity in creating safe, respectful physical activity spaces that meet theirs and their parents' needs. For example, Fizzy's tale demonstrates her mother's 'veiling-off' (Hamzeh, 2011) or prevention of her attending some after school physical activity clubs because of concerns regarding whom she socialises with. However, Fizzy finds alternative physical activity settings to ensure she does not violate the hijabs. These involve trampolining at home and playing basketball and football in her locality with friends that are known to her mother.

.... she wasn't happy when I went after school 'cause I didn't get home till five. Wanted to know where I'd been, what I'd been up to, who I was with. She's a bit strict 'cause she doesn't know my school friends, but they're like me. Not bothered with boys or anything and we look out for each other ...... She can't use the "I don't know what you're doing or who you're with" excuse 
'cause she can see me from the flat when I play out there. And it's just with boys and girls from the area so she knows them.

Similarly, Noreen proactively searches for and experiments with spaces and activities that do not cross the spatial and ethical hijabs as interpreted by her family.

I love my bedroom! It means a lot to me 'cause it's where I feel relaxed and can do whatever I want. But l'd still prefer to be going boxing. It's not like my brothers are even bothered about it. Dad only takes them to get them from under Mom's feet, burn off all that energy, before they start fighting. But don't think he's keen for me to go, what with older guys being there. He'd have offered otherwise.

Such was Noreen's desire to box, she describes the compromise she had found, using the privacy of her garage at home and her brothers' boxing bag. This enables her to constitute her sporty identity in a way that prevents her from violating the visual, spatial and ethical dimensions of the hijab discourse as constructed by her family. Noreen's narrative provides further evidence of the ways she negotiates the hijabs in other activities. These include dancing in the privacy of her bedroom, and running in the dark to avoid the surveillance from some members of her community.

It's dark enough, so the old women won't stare from their windows ..... They make you feel like you're doing something wrong when you're not. Like that time me and Ikram (brother) were playing badminton in the street. That guy from down the road took over from Ikram and Aunty saw and had a fit, so I had to go inside. It's so annoying.

The excerpts from the young women's stories reflect the significance of the structural, disciplinary and hegemonic domains of power and how these intersect to 
influence interactions and experiences at the interpersonal level (Hill Collins, 2000). Multiple interpretations of the hijab discourse circulate within the hegemonic domain, and surveillance by family, friends, community and other relatives within the disciplinary domain enforces the three hijabs. In turn, these influence the young women's actions, dress, and mobility at the interpersonal level (Hill Collins, 2000). The young women also reflect how these interpretations can shift with changes often contingent on context, including people present and activity to be undertaken. Like those in Hamzeh's study $(2011 ; 2012)$, the young women in this research demonstrate their ability to navigate and negotiate the complexities of these multiple and shifting interpretations. Their stories reflect their 'deveiling' of the three hijabs in their questioning and actions. They demonstrate the possibilities that can arise through creating spaces that support their right to engage in physical activity and embody their religion in diverse ways.

\section{Conclusion}

The young women's stories reflect the complex interplay of multiple influences and discourses on their physicality. Parents, siblings, friends, extended family and wider community members intersect with religion, physical activity, gender and different cultural beliefs to create challenges and opportunities for them to be physically active. The young women demonstrate how the hijab discourse with its multiple dimensions and shifting interpretations, contingent upon context and activity, adds a further complexity to their experiences (Hamzeh, 2011; 2012). These findings point to the need for future research to more fully consider the variety of influences and discourses across diverse settings to develop understandings of South Asian, Muslim young women's experiences. This challenges homogenised and deficit ways of thinking around their physical activity involvement, as do the stories of the young 
women presented here, which problematise the notion of collective identities. In reflecting the differences between and within families, their narratives highlight that being South Asian and/ or Muslim are not indicators of a homogenous group (Shain, 2003). Different degrees of religiosity and varying interpretations of the hijab discourse reflect the divergencies within their collective 'South Asian, Muslim' identity. The diverse ways in which the young women and their families practice and embody their faith, are reflected in their equally diverse stories of physical activity involvement.

The study points to the importance of the physical activity setting, and contexts that are inclusive of the young women's multiple identities, and their right to take part in physical activity. However, the research highlights the contested nature of what is considered an appropriate space. These findings support Benn et al's (2011) call for physical activity providers and pedagogues to adopt a more proactive approach through collaboration with the communities they serve in order to acknowledge and accommodate differences. This would involve consulting with all community members, including parents, religious leaders, but perhaps more importantly, the young women themselves. Finally, these findings cohere with previous studies (Knez et al., 2012; Walseth, 2006), that move away from participation data that defines particular groups of young people, including South Asian, Muslim young women, in narrow deficit terms. Rather, the young women's narratives provide counter stories that reflect their desire to be involved in physical activity and their strategies for enabling this to happen. These insights are important if we wish to facilitate meaningful and life-long enjoyment of physical activity for the young women and their families. 


\section{References}

Archer, L., Hutchings, M., \& Leathwood, C. (2001). Engaging with Commonality and Difference: theoretical tensions in the analysis of working-class women's educational discourses. International Studies in Sociology of Education, 11 (1), 41-62.

Azzarito, L., \& Hill, J. (2013). Girls looking for a 'second home': bodies, difference and places of inclusion. Physical Education and Sport Pedagogy, 18 (4), 351375.

Benn, T., Pfister, G., \& Jawad, H. (Eds.). (2011). Muslim Women and Sport. Oxon: Routledge.

Buswell, L., Zabriskie, R. B., Lundberg, N., \& HAWKINS, A. J. (2012). The Relationship Between Father Involvement in Family Leisure and Family functioning: The Importance of Daily Family Leisure. Leisure Sciences: An Interdisciplinary Journal, 34 (2), 172-190.

Clark, A., \& Moss, P. (2011). Listening to Young Children: The Mosaic Approach. London: NCB.

Dagkas, S., Benn, T., \& Jawad, H. (2011). Multiple voices: improving participation of Muslim girls in physical education and school sport. Sport, Education and Society, $16(2), 223-239$.

Department for Culture, Media \& Sport. (2011). Adult participation in sport: Analysis of the Taking Part Survey. London: DCMS.

Dowling, F. (2012). A narrative approach to research in physical education, youth sport and health. In F. Dowling, H. Fitzgerald, \& A. Flintoff (Eds.). Equity and Difference in Physical Education, Youth Sport and Health. Oxon: Routledge.

Flintoff, A., Fitzgerald, H., \& Scraton, S. (2008). The challenges of intersectionality: researching difference in physical education. International Studies in Sociology of Education, 18 (2), 73-85.

Greig, A., Taylor, J., \& MacKay, T. (2007). Doing Research with Children. London: Sage Publications Ltd.

Hamzeh, M. (2011). Deveiling body stories: Muslim girls negotiate visual, spatial, and ethical hijabs. Race Ethnicity and Education, 14 (4), 481-506.

Hamzeh, M. (2012). Pedagogies of Deveiling: Muslim Girls and the Hijab Discourse (Critical Construction., Charlotte, N.C: Information Age Publishing. 
Harrington, M. (2009). Sport mad, good dads. Australian fathering through leisure and sport practices. In T. Kay (Ed.), Fathering Through Sport and Leisure (pp. 51-72). London: Routledge.

Haycock, D., \& Smith, A. (2012). A family affair? Exploring the influence of childhood sport socialisation on young adults' leisure-sport careers in north-west England. Leisure Studies, 33 (3), 285-304.

Hill Collins, P. (2000). Black Feminist Thought: Knowledge, Consciousness, and the Politics of Empowerment. London: Routledge.

hooks, b. (1982). Ain't I a Woman: Black Women and Feminism. London: Pluto Press.

Kay, T. (2006). Daughters of Islam: Family Influences on Muslim Young Women's Participation in Sport. International Review for the Sociology of Sport, 41 (3), 357-373.

Kay, T. (Ed.). (2009). Fathering Through Sport and Leisure. Oxon: Routledge.

Knez, K., Macdonald, D., \& Abbott, R. (2012). Challenging stereotypes: Muslim girls talk about physical actvity, physical education and sport. Asia-Pacific Journal of Health, Sport and Physical Education, 3 (2), 109-122.

Lincoln, Y. S., \& Guba, E. G. (1985). Naturalistic Inquiry. Beverley Hills, CA: Sage.

McNay, L. (1992). Foucault \& Feminism. Cambridge: Polity Press.

O'Sullivan, M., \& MacPhail, A. (Eds.). (2010). Young People's Voices in Physical Education and Youth Sport. Oxon: Routledge.

Rapoport, R., \& Rapoport, R. N. (1975). Leisure and the Family Life Cycle. London Routledge and Kegan Paul Ltd.

Shain, F. (2003). The schooling and identity of Asian girls. Staffordshire: Trentham Books.

Shaw, S. M. (2008). Family leisure and changing ideologies of parenthood. Sociology Compass, 2 (2), 688-703.

Smith, B., \& Sparkes, A. (2008). Narrative and its potential contribution to disability studies. Disability and Society, 23 (1), 17-28.

Stride, A. (2014a). Centralising space: The physical education and physical activity experiences of South Asian, Muslim girls. Sport, Education and Society. DOI: 10.1080/13573322.2014.938622

Stride, A. (2014b). Let US tell YOU! South Asian, Muslim girls tell tales about physical education. Physical Education and Sport Pedagogy, 19 (4), 398-417. 
Trussell, D. E., \& Shaw, S. M. (2012). Organized Youth Sport and Parenting in Public and Private Spaces. Leisure Sciences: An Interdisciplinary Journal, 34 (5), 377-394.

Walseth, K. (2006). Young Muslim Women and Sport: the Impact of Identity Work. Leisure Studies, 25 (1), 75-94.

Watson, B., \& Scraton, S. (2001). Confronting Whiteness? Researching the leisure lives of South Asian mothers. Journal of Gender Studies, 10 (3), 265-277.

Weedon, C. (1997). Feminist Practice and Poststructuralist Theory. Oxford: Blackwell Ltd.

Wheeler, S. (2011). The significance of family culture for sports participation. International Review for the Sociology of Sport, 47 (2), 235-252.

\section{Notes}

\footnotetext{
${ }^{1}$ Hamzeh (2012, p. 1) notes her alternating use of the terms Muslim and muslim is a conscious act to reflect the fluidity of cultural expressions found within different communities. She also adds that the italicised version of the word is used to denote a political and analytical category useful in counter hegemonic struggles.

${ }^{2}$ Stonefields is a fictitious name given to a large urban conurbation in Yorkshire, England.

${ }^{3}$ Student demographic information was obtained through internal school reports and databases that have remained unreferenced here to ensure the school's anonymity. ${ }^{4}$ All names have been changed and the pseudonyms were chosen by the young women.
} 